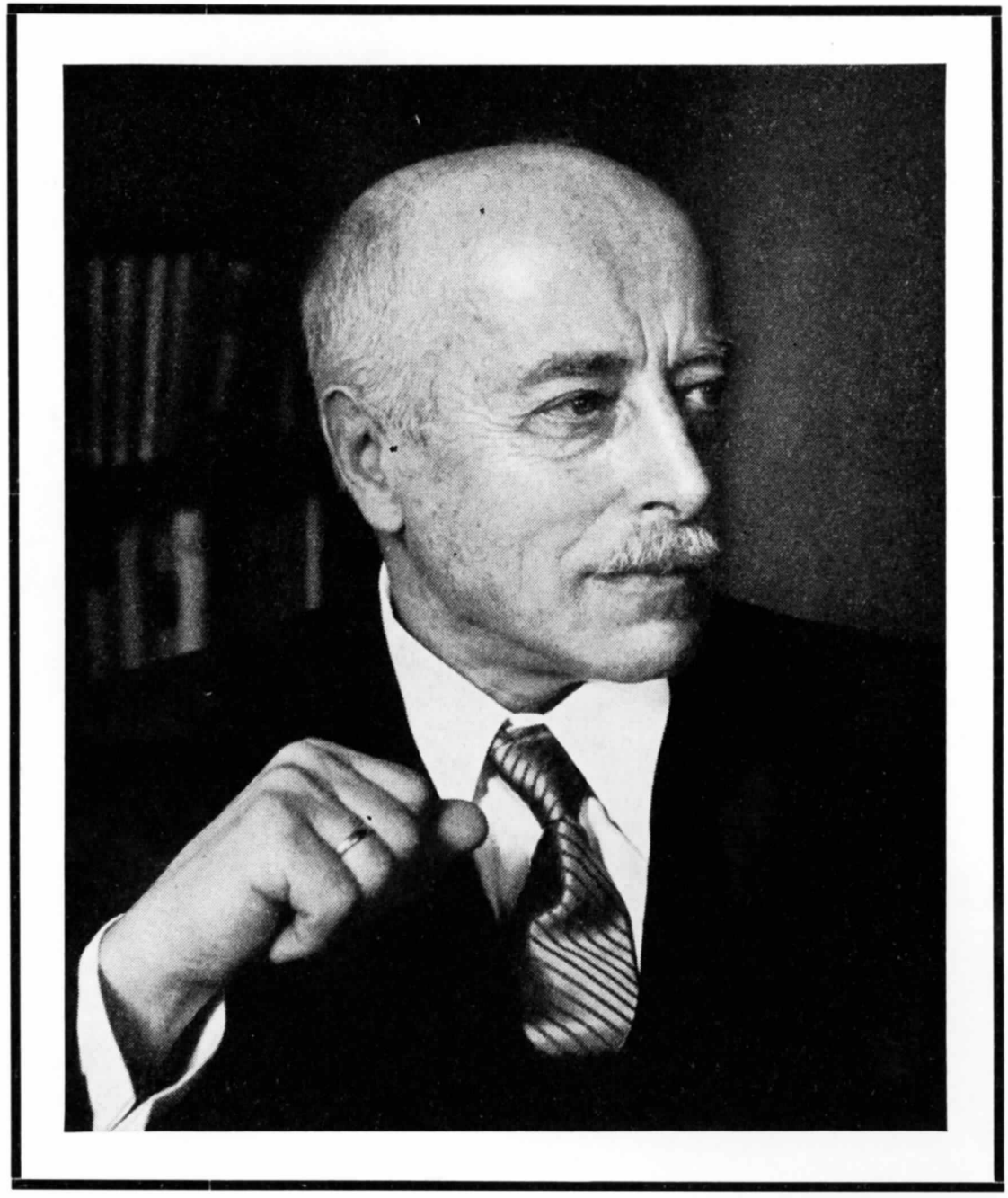

\title{
MAX von LAUE
}

$$
1879-1960
$$

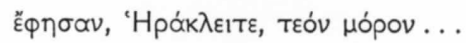

They told me, Herakleitos, they told me you were dead...

It is hard to believe that Max von Laue is no longer among us. He succumbed on 24 April to injuries suffered in a car accident on 8 April. In him, we have lost a great leader in scientific thought, a champion of intellectual integrity, a true friend, and an upright man. In each of these respects he has had few peers and the world is the poorer for his tragic death.

On 9 October, last year, von Laue's eightieth birthday was celebrated in Berlin-Dahlem in the Fritz Haber Institute of the Max Planck Gesellschaft, which Laue had, until recently, directed. This was a happy and harmonious day. Among the guests were the two co-octogenarians Lise Meitner and Otto Hahn. To watch these venerable veterans of Science and longtime friends engaged in lively and often challenging conversation, seemingly unaffected by the passage of years, was a wonderful example and inspiration for old and young friends and associates.

What Laue has meant for X-ray Crystallography need hardly be explained to the readers of this journal. His discovery of X-ray diffraction by crystals opened up a most topical field of research at the very time when the quantum theory of atoms was in its earliest infancy. Vigorously pursued in two directions, two 
new branches of Physics grew out of his work: CrystalStructure Analysis in the hands of W. H. and W. L. Bragg, and X-ray Spectroscopy through the work of Moseley, M. de Broglie, M. Siegbahn and others. While it took many years until the super-stereochemistry of crystal-structure analysis could be quantitatively linked to the wave-mechanical theory of the chemical bond, the results of $\mathrm{X}$-ray spectroscopy on atomic energy levels provided an immediate and most valuable check on the latest stages of the rapidly developing atomic theory.

Laue himself took no part in the progress of crystalstructure analysis. He shared to some extent, though not to the same degree, Lord Rutherford's feeling that working out the details of a structure was not a problem of the fundamental type which appealed to him. Once the diffraction experiments had clearly indicated the periodic internal structure of crystal, as assumed in the structure theories, and the wave nature and wavelength of X-rays as discussed by Wien and Sommerfeld, this chapter of physics was satisfactorily, if temporarily, closed for him. Indeed, soon after the publication of the two papers in the Bavarian Academy, Laue started on a purely optical diffraction experiment of an entirely different type.

This rather surprising indifference to the elaboration of his discovery for the advancement of Solid-State Physics and of Theoretical Chemistry contrasts strongly with Laue's keen interest in X-ray Optics, which lasted throughout the whole span of 48 years after his first work. A few of the $\mathrm{X}$-ray optical topics of Laue's papers may be mentioned: the generalization of the concept of the reciprocal lattice to non-orthogonal crystals; the connection of line width and particle size; the effect of particle shape in producing intensity spikes in reciprocal space; the re-formulation of the dynamical theory in terms of Fourier coefficients; the discussion of the possible influence of the Doppler frequency shift caused by the thermal motion of the atoms; and a final series of important papers on absorption in the case of simultaneous existence of more than one ray in the crystal. This last topic was worked out by Laue while he was interned, together with a group of German nuclear physicists, near Cambridge in 1946; the manuscript was handed to the Editor of Acta at the Harvard meeting in 1948 at which the International Union of Crystallography was constituted with Laue nominated its first and only Honorary President. The paper appeared in
Acta Cryst. 2, 106, and gives the theory of the Borrmann effect; it was succeeded by several recent papers on the closely related topic of energy flow in the case of interference.-In two books Laue has collected and systematized his research in the fields of X-ray and electron crystal optics. 'Röntgenstrahlinterferenzen' first appeared in 1941 and in its third edition in 1960, after Laue's accident but still in time for him to acknowledge it, and 'Materiewellen und ihre Interferenzen' in 1944. These books are likely to remain the standard monographs in their fields. As in Laue's first monograph, 'Das Relativitätsprinzip' (Vol.1 1911 and later editions, Vol. 2 1921), a great wealth of Laue's own work is contained in these books, and problems often skipped over in other presentations are discussed and worked out in detail in a spirit of painstaking honesty and responsibility of the author towards his readers.

Laue was, and considered himself, a physicist, not a crystallographer or other specialist. The fields in which his main achievements lie are Thermodynamics and Theory of Radiation, Relativistic Electrodynamics and Optics, Theory of Space Charges in Electronic Tubes, and Superconductivity. He was lecturer (Privatdozent) in Berlin and Munich (1908-12), Professor in Zürich (1912-14), Frankfurt (1914-19) and Berlin (1919-43). From 1922 to 1943 he was acting director of the Kaiser Wilhelm (later Max Planck) Institute of Physics, and from 1951-58 Director of the Fritz Haber Institute of the Max Planck Gesellschaft. Laue received the Nobel Prize for Physics in 1914, the Max Planck Medal in 1932 and the Helmholtz Medal of the Deutsche Alkademie on his birthday in 1959. The hereditary nobility was bestowed on his father, a high officer in the quartermaster service of the army, in 1913, and bears no direct relation to Laue's work. But on his seventieth and eightieth birthdays, Laue received high civic distinctions. $\mathrm{He}$ was awarded honorary degrees and memberships of Scientific Societies and Academies, among them the Royal Society (1949).

The picture of Laue would be very incomplete without mention of his great merits in organizational work for Science. He was, at various times, among the editors of Zeitschrift für Kristallographie, Zeitschrift für Physik, Annalen der Physik. When, soon after the first world war, American money became available to a specially created commission of the Notgemeinschaft der Deutschen Wissenschaft, Laue was placed in charge 
of it. One of its major subsidies went to the preparation of the Strukturbericht. It would be a difficult but rewarding task to trace Laue's influence on the progress of Physics in his wide-spread committee work. When organization of science in Germany was not only in ruins at the end of the second world war, but also severely restricted by the occupation powers, the gradual emergence of regional Physical Societies and their eventual consolidation was largely due to Laue's prudent and determined counsel. From 1946 to 1948 one of his main endeavours was the re-constitution of the Physikalisch-Technische Reichsanstalt, formerly Charlottenburg, the prototype of National Physical Laboratories, founded by Helmholtz, Siemens and others. During the war, this institution had been scattered throughout Germany; that these parts could be reassembled as the present Physikalisch-Technische Bundesanstalt in Braunschweig is in no small part due to Laue's efforts.

The probity of Laue's character suffered no inflexion during the Hitler régime. While many respectable scientists yielded to political pressure, first outwardly 'aligning' themselves and in the end losing their spiri- tual independence, Laue was neither to be threatened nor bribed into subservience. On many private occasions and in two famous public addresses his voice rang out like a clarion call for liberty of thought and against oppression. Nobody who has not himself lived in the atmosphere of distrust and fear of the Hitler régime can appraise what clever and courageous deeds Laue's pronouncements at the opening of the Physics Meeting in Würzburg in September 1933 and at the (officially forbidden) commemoration gathering for Fritz Haber (1934) were. Unknown but large is the number of those scientists whose painful process of emigration was quietly and efficiently eased by Laue's advice and actual help. Laue was a great patriot and he clearly recognized Germany's loss in the eviction of so many of her best-trained scientists. But his human loyalty was even stronger than the patriotic appeal. As to himself, he found he had to stay where his duty lay, and that was to save from ruin what could be saved.

Max von Laue's example, as a scientist and a man, will continue to shine bright.

P. P. Ewald. 